\title{
Maternal Mortality and Its Causes in a Tertiary Center
}

\author{
Khumanthem Pratima Devi • \\ Chanam Manglem Singh • \\ Samjetshabam Randhoni Devi
}

Received: 6 April 2010/Accepted: 2 April 2012/Published online: 1 June 2012

(C) Federation of Obstetric \& Gynecological Societies of India 2012

\begin{abstract}
Objectives To study the maternal mortality and the complications leading to maternal death.

Methods A retrospective study of hospital records and death summaries of all maternal deaths over the period from January 2000 to August 2009 was carried out.

Results There were a total of 80 maternal deaths out of 88,443 live births giving maternal mortality rate (MMR) of 90.45 per 100,000 live births. Unbooked and late referral accounted for $77.5 \%$ of maternal deaths. The majority of the deaths was in 30-40-year age group and around term. Hemorrhage was the commonest cause of death (52.5\%), followed by sepsis $(13.75 \%)$ and pregnancy-induced hypertension including eclampsia (10\%).

Conclusions Hemorrhage, sepsis, and pregnancy-induced hypertension including eclampsia were found to be the direct major causes of death. Anemia and cardiac disease were other indirect causes of deaths.
\end{abstract}

Khumanthem P. D., Registrar · Chanam M. S., Prof. \& Head · Samjetshabam R. D., Assoc. Prof.

Department of Obstetrics and Gynecology, Regional Institute of Medical Sciences (RIMS), Lamphel, Imphal,

Manipur 795001, India

Khumanthem P. D. ( $\square)$, Registrar

C/O Dr. A.D. Sharma, Brahmapur Aribam Leikai,

Near Water Tank, Imphal, Manipur 795001, India

e-mail: pratimadutta09@gmail.com
Keywords Maternal mortality · Postpartum hemorrhage · Sepsis $\cdot$ Eclampsia $\cdot$ Anemia

\section{Introduction}

Maternal death is a tragic situation as it occurs during or after a natural process. It is the leading cause of death for women of reproductive age group. The index of the quality of health care delivery system of a country as a whole or in part is reflected by its maternal mortality rate (MMR). With $16 \%$ of the world's population, India accounts for over $20 \%$ of the world's maternal deaths. Every minute everyday, a woman dies as a result of pregnancy and childbirth somewhere in the world. Every year, approximately 600,000 women die of pregnancy-related causes, and $98 \%$ of these deaths occur in developing countries [1]. The MMR per 100,000 live births is estimated to be 920 in Africa, 330 in Asia, and 10 in Europe [2]. Up to $80 \%$ of these deaths are directly due to five complications: hemorrhage, sepsis, pregnancy-induced hypertension, rupture uterus (obstructed labor), and complications of abortion. A major reason for so many deaths due to hemorrhage is because, once bleeding starts, death can occur in around $2 \mathrm{~h}$ compared with $10 \mathrm{~h}$ for eclampsia and $72 \mathrm{~h}$ for obstructed labour [3].

The United Nations issued 8 Millennium Development Goals (MDG); the fifth goal (MDG-5) stipulated a reduction of the MMR by $75 \%$ by 2015 [4]. In India too, the National Health Policy, 2002 aims toward reducing the 
MMR to $100 / 1$ lakh by 2010 , while the National Rural Health Mission (NRHM) sets similar targets to be achieved by 2012. The level of MMR in India has declined from over 750 in the 1960s to about 400 in the 1990s [5, 6]. It is roughly estimated to be about 300 in 2003 , though it is above 400 in some states [7, 8]. Preventing maternal deaths remains one of the most important objectives of the National Family Welfare Program. Efforts for monitoring are limited due to lack of population-based reporting of vital events. Most of the evidence for maternal mortality is obtained through hospital data and community-based reports, both of which have limitations. By accessing the information that is available, it is possible to assess the magnitude and pattern of the health problem in the state [9].The aim of study was to assess the MMR in the tertiary center and find out the causes leading to maternal deaths.

\section{Materials and Methods}

The study was conducted by reviewing the records for deaths over the period from January 2000 to August 2009 in the department of Obstetrics and Gynecology at Regional Institute of Medical Sciences, Imphal. Every maternal death was scrutinized from various aspects likely to be related to death, such as age, locality of residence, parity, literacy, antenatal care, admission-death interval, and the cause of death.

\section{Results}

During the study period, there were 80 maternal deaths out of 88,443 live births giving an MMR of 90.45 per 100,000 live births (Table 1). Seventy percent of these deaths were in the postnatal period, and $28.75 \%$ of deaths were due to

Table 1 Year wise distribution of maternal deaths and live births

\begin{tabular}{cccc}
\hline Year & Maternal deaths & Live births & MMR \\
\hline 2000 & 5 & 6,833 & 73.17 \\
2001 & 7 & 7,904 & 88.56 \\
2002 & 12 & 8,412 & 142.65 \\
2003 & 6 & 10,408 & 57.65 \\
2004 & 8 & 9,868 & 81.07 \\
2005 & 7 & 10,229 & 68.43 \\
2006 & 8 & 10,933 & 73.17 \\
2007 & 11 & 8,863 & 124.11 \\
2008 & 6 & 8,900 & 67.42 \\
$2009^{\text {a }}$ & 10 & 6,096 & 164 \\
Total & 80 & 88,443 & 90.45 \\
\hline
\end{tabular}

${ }^{\text {a }}$ Up to August 2009 only home delivery and late transport. As shown in Table 2, $77.5 \%$ were unbooked and belonged to rural areas. A majority of the deaths had occurred at term $(57.5 \%)$ and were multigravida (75\%), while $57.5 \%$ of deaths were in age group of $30-40$ years. Also majority of them (77.5\%) were illiterate.

As seen from Table 3, 48 maternal deaths $(60 \%)$ had occurred within the first $24 \mathrm{~h}$ of admission. Analysis of the causes of death revealed that obstetrical hemorrhage is the leading cause of death (Table 4). Out of 80 deaths, 42 $(52.5 \%)$ were due to hemorrhage; sepsis-related deaths due to late referral were $11(13.75 \%)$; and pregnancyinduced hypertension- or eclampsia-related deaths were 8 $(10 \%)$. Amniotic fluid embolism was suspected in 3 $(3.75 \%)$ and pulmonary embolism in another $3(3.75 \%)$. Only one woman died because of acute uterine inversion. Among 42 deaths due to hemorrhage, 15(18.75\%) were due to atony and $5(6.25 \%)$ due to antepartum hemorrhage. In about $12(15 \%)$, deaths were due to indirect causes like anemia, cardiovascular disease, hepatitis, asthma, epilepsy, acute renal failure, and terminal stage of carcinoma breast.

Table 2 Maternal deaths and its characteristics

\begin{tabular}{llll}
\hline Characteristics & Groups & $\begin{array}{l}\text { Maternal } \\
\text { deaths }\end{array}$ & Percent \\
\hline Age (Years) & $10-20$ & 3 & 3.75 \\
& $20-30$ & 26 & 32.5 \\
& $30-40$ & 46 & 57.5 \\
& $>40$ & 5 & 6.25 \\
Parity & Primi & 20 & 25 \\
& Multi & $60(16)$ & $75(20)$ \\
Antenatal care & Booked & 18 & 22.5 \\
& Unbooked & 62 & 77.5 \\
Locality & Rural & 62 & 77.5 \\
& Urban & 18 & 22.5 \\
Gestational & $<20$ & 7 & 8.75 \\
age (weeks) & $20 \leq 37$ & 31 & 38.75 \\
& $\geq 37$ & 46 & 57.5 \\
\hline
\end{tabular}

Table 3 Admission to death interval

\begin{tabular}{llc}
\hline $\begin{array}{l}\text { Admission death } \\
\text { interval in hours }\end{array}$ & $\begin{array}{l}\text { No. of } \\
\text { maternal } \\
\text { deaths }\end{array}$ & Percentage \\
\hline 24 & 48 & 60 \\
$24-48$ & 14 & 17.5 \\
$48-72$ & 6 & 7.5 \\
$>72$ & 12 & 15 \\
\hline
\end{tabular}


Table 4 Causes of maternal deaths $(n=80)$

\begin{tabular}{|c|c|c|}
\hline Causes & No. of deaths & Percentage \\
\hline Direct & 68 & 85 \\
\hline Hemorrhage & 42 & 52.5 \\
\hline Atony & 15 & 18.75 \\
\hline Antepartum hemorrhage & 5 & 6.25 \\
\hline Uterine rupture(Obstructed) & 5 & 6.25 \\
\hline Abortion & 5 & 6.25 \\
\hline Ectopic rupture & 2 & 2.5 \\
\hline Following cesarean & 2 & 2.5 \\
\hline Molar pregnancy & 2 & 2.5 \\
\hline DIC & 3 & 3.75 \\
\hline Adherent placenta & 3 & 3.75 \\
\hline Sepsis & 11 & 13.75 \\
\hline Pregnancy-induced hypertension & 8 & 10 \\
\hline Amniotic fluid embolism & 3 & 3.75 \\
\hline Pulmonary embolism & 3 & 3.75 \\
\hline Acute uterine inversion & 1 & 1.25 \\
\hline Indirect & 12 & 15 \\
\hline Anemia & 3 & 3.75 \\
\hline Cardiovascular disease & 3 & 3.75 \\
\hline Hepatitis & 2 & 2.5 \\
\hline Asthma & 1 & 1.25 \\
\hline Epilepsy & 1 & 1.25 \\
\hline Acute renal failure & 1 & 1.25 \\
\hline Terminal stage of malignancy & 1 & 1.25 \\
\hline
\end{tabular}

\section{Discussion}

The MMR in our present study is 90.45 per 100,000 live births, ranging from 73.17 in 2000 to 164 in 2009. Most women were from far-off places resulting in delayed intervention, and many were in poor general condition at the time of admission. Other studies from tertiary care institutions reported mortality rate of $371-4286 / 100,000$ live births due to large number of referred cases [10]. Also some deaths which occurred outside the medical system were not included, and this led to a different incidence from the actual one occurring in the community. We might have underestimated the levels of maternal mortality, either because death reporting was incomplete or because pregnancy was underreported as a cause of death. The higher incidence of deaths is due to late referral of cases from periphery and delayed intervention. Most deaths were observed in the 30-40-year age group in the present study, whereas deaths were in the 21-30-year age group in other studies [11]. Older age group was due to late marriage, and many were grand multigravida. Sixty percent of deaths occurred within the first $24 \mathrm{~h}$ of admission to the hospital.
Postpartum deaths accounted for about $70 \%$. Hemorrhage was the commonest cause of death $(52.5 \%)$, and this is comparable with most of the other studies. The availability of blood banks at all first referral units (FRUs) and their proper functioning are needed. The provision of timely blood transfusions can save many lives [12].

Hemorrhage and sepsis were the major direct killers and were comparable to other studies $[8,12]$. Sepsis accounted for about $13.75 \%$ which included both puerperal sepsis due to home delivery and septic abortion due to Medical Termination of Pregnancy done outside. Many of these lives could have been saved, if all abortions and deliveries were performed by qualified medical personnel [10]. Hypertension or eclampsia-related deaths accounted for another $10 \%$ of deaths, which is comparable with other studies [11, 13]. The use of magnesium sulfate and early termination with medications had led to improve the scenario of eclampsia. Amniotic fluid and pulmonary embolism were responsible for $3.75 \%$ each. Only one woman had died because of inversion of uterus, and this is similar with the study reported by Jagdish and Govind [9].

Indirect causes of death accounted for $15 \%$, out of which anemia and cardiovascular causes had constitute the majority. Preexisting anemia worsens as pregnancy advances leading to heart failure and death. It also impedes the mother ability to resist infection or cope with hemorrhage and increases the likelihood of her dying in childbirth by a factor of four [10]. Hepatitis accounted for $2.5 \%$ deaths. $4.16-10.8 \%$ deaths have been reported in other studies $[10,11]$.

\section{Conclusion}

What is tragic is that most of these deaths are preventable. Maternal deaths are still high in comparison with developed countries. Sustained reductions in maternal mortality will only be possible if modern high-quality obstetric care is made available to all women through a system of professional midwifery and referral hospital care in the context of political commitment and accountability of health providers. A recent systemic review of the causes of death stressed the need for increased emphasis on prevention and treatment of obstetric hemorrhage and noted that most post-partum deaths should be avoidable by appropriate management [14]. Much needs to be done for maternal health care in rural areas, as most of the deaths reported are referral from peripheral centers. Concentrated efforts are required to obtain the missing data through improvising better and accurate data collection. Heath education of masses along with good quality health care and transport facilities can prevent many deaths. 


\section{References}

1. Rao KA. Presidential address. The 44th All India Obstetric and Gynecological congress. Ahmadabad. December 27, 2000. J Obstet Gynecol India 2001;51:25-8.

2. WHO/UNICEF/UNFPA. Maternal mortality in, 2005 estimates developed by WHO, UNICEF, UNFPA and the world bank. Geneva: WHO; 2007.

3. AICOG Committee Opinion. Number 283, May 2003. New US. Food and drug administration labeling on cytotec (misoprostol) use and pregnancy. Obstet Gynecol. 2003;101:1049-50.

4. United Nations. UN Millennium Development Goals web site. http://www.un.org/millenniumgoals/. Accessed 1 August 2009.

5. Bhat PN, Navneetham K, Rajan SI. Maternal mortality in India: estimates from a regression model. Stud Fam Plann. 1995;26: 217-32.

6. Bhat PN. Maternal mortality in India: an update. Stud Fam Plann. 2002;33:227-36.

7. Registrar General of India. Maternal mortality in India: 1997-2003. Trends, causes and risk factors, Report 2006, Registrar General India: New Delhi, p 1-29.
8. Singh P, Pandey A, Aggarwal A. House-to-house survey vs. snowball technique for capturing maternal deaths in India: a search for cost-effective method. Indian J Med Res. 2007;125: $550-6$.

9. Jagdish JA, Govind RP. Maternal mortality: changing trends. J Obstet Gynecol. 2007;57:398-400.

10. Bedi N, Kambo I, Dhillon BS, et al. Maternal deaths in India: preventable tragedies. (An ICMR Task Force Study). J Obstet Gynecol India. 2001;51:86-92.

11. Ashok V, Santosh M, Anupa S. A study on maternal mortality. J Obstet Gynecol. 2008;58:226-9.

12. Bates I, Chapotera G, McKew S, et al. Maternal mortality in subSahara Africa: the contribution of ineffective blood transfusion services. BJOG. 2008;115:1331-9.

13. Aggarwal Abha, Pandey Arvind, Bhattacharya BN. Risk factors for maternal mortality in Delhi slums: a community-based case control study. Indian J Med Sci. 2007;61:517-26.

14. Khan KS, Wojdyla D, Say L, et al. WHO analysis of causes of maternal death: a systematic review. Lancet. 2006;367:1066-74. 